\title{
Statistics and Probability at Secondary Schools in the Federal State of Salzburg: An Empirical Study
}

\author{
Wolfgang Voit \\ University of Salzburg
}

\author{
Arne C. Bathke \\ University of Salzburg
}

\begin{abstract}
Knowledge about the practical use of statistics and probability in today's mathematics instruction at secondary schools is vital in order to improve the academic education for future teachers. We have conducted an empirical study among school teachers to inform towards improved mathematics instruction and teacher preparation. The study provides a snapshot into the daily practice of instruction at school. Centered around the four following questions, the status of statistics and probability was examined. Where did the current mathematics teachers study? What relevance do statistics and probability have in school? Which contents are actually taught in class? What kind of continuing education would be desirable for teachers? The study population consisted of all teachers of mathematics at secondary schools in the federal state of Salzburg.
\end{abstract}

Keywords: high school, mathematics education, secondary school, teacher.

\section{Introduction and motivation}

The Department of Mathematics at the University of Salzburg offers, in addition to Bachelor's, Master's, and PhD degrees in Mathematics, also a study program for secondary school mathematics instruction, resulting in Bachelor's and Master's degrees in Mathematics Education. For this program, courses in probability and statistics have been in existence for several years, specially designed with the intention of providing effective and up-to-date teacher training. As school curricula are being adjusted, also university curricula for teacher education need to adapt. A major change in Austrian secondary school education is the current introduction of a central school leaving examination (Matura), combined with the call for the formulation of competence oriented learning objectives in school. At the same time, the role and importance of statistics in secondary school mathematics classes have gradually increased over the last years. Universities offering mathematics teacher training thus need to adapt to these changes occurring in the secondary education landscape. However, once teachers leave the university training, they are generally not available to provide feedback to their alma mater, as continuing education for Austrian school teachers is typically not provided by the universities, but by a system of teacher training colleges (Pädagogische Hochschulen). While much data is collected regularly based on surveying students, a comprehensive survey of mathematics school teachers in Austria, not to mention an up-to-date one, is not known to the authors. 
Thus, the university departments are lacking up-to-date information on the actual demands and practice in school instruction, and this has motivated the present empirical study involving secondary school mathematics teachers in the Austrian Federal State of Salzburg. The teachers were contacted to provide feedback on issues centered around the following key questions.

1. At which universities or colleges, and with which perceived quality of preparation, did current Mathematics teachers in Salzburg receive their training?

2. What role do probability and statistics currently play in school teaching?

3. What specific (probabilistic/statistical) content is actually covered in secondary school mathematics instruction?

4. What are the continuing education needs of school teachers with regard to probability and statistics?

These questions make it clear that the goals of the study were different from those trying to assess knowledge or professionalism of mathematics teachers (see, e.g. Blömeke, Kaiser, and Lehmann 2008; Krauss, Brunner, Kunter, Baumert, Blum, Neubrand, and Jordan 2008, and references cited therein). Simply said, in the present study, the questions were not centered around "what do mathematics teachers know?", but rather "what do mathematics teachers teach, and do they feel prepared for teaching it?". The authors were mostly interested in the subject of statistics and how it is taught in school, but statistics and probability are very closely related in secondary school mathematics in German speaking countries. Therefore, both topics were explicitly included in the study.

In the following, the results of the empirical study are presented, along with several details on how it was performed. The survey and all communication with teachers and school administrators was conducted in German. Survey responses or answer categories quoted below have been translated for this article. The original answer categories in German can be obtained from the first author upon request.

\section{Conducting the survey}

The survey was conducted from January to June 2013 and evaluated as part of the diploma thesis of the first author (Voit 2013). All mathematics teachers at the 66 secondary schools in the Federal State of Salzburg were contacted and asked to fill out the survey. There are currently about 250 mathematics teachers in Salzburg. The exact number of people teaching mathematics in any given year is not known, as not everyone who has studied mathematics education actually teaches this subject every year. Typically secondary school teachers are trained to teach two subjects. Some are in practice actually only teaching one of those, and some are mostly teaching one subject, and rarely the other. The estimate of 250 is calculated as follows: the federal statistics agency Statistik Austria publishes the number of teachers per school type for each state (Statistik Austria 2012a). For each school type, the proportion of mathematics instruction hours as part of the total hours of instruction is known, based on standard curricula (bmukk 2003). Assuming that the proportion of mathematics teachers among all teachers corresponds roughly to the proportion of mathematics instruction hours among all hours, the above estimate is obtained. This approach was validated using the course schedule of two schools known to the first author: in one of these schools, 40 out of 370 total instruction hours were mathematics, and 8 of 74 teachers were mathematics teachers. Both proportions are equal (10.8\%). In the other school, 21 of 415 hours (5.0\%), and 2 of 38 teachers $(5.3 \%)$ correspond to mathematics. Both examples suggest that the used method of approximating the number of mathematics teachers per school is reasonable. 
In order to obtain a large response rate, a combination of different strategies was used. The respective school supervisory board members as well as school directors were asked for permission and support. Further, most schools in the city of Salzburg were visited in person, and paper surveys were hand-delivered. Schools in the countryside were contacted via email, but it was requested that the surveys were printed and handed to the mathematics teachers in paper form. The decision to use paper surveys stems from the fact that teachers nowadays often get inundated with email requests for participation in surveys which may obviously get deleted and forgotten quickly. In order to differentiate the effect of personal visit vs. email request on response rate from the possible effects of urban vs. rural setting, a few schools in the city served as a control group and received the survey electronically, in the same way as all the rural schools. Survey results were picked up personally in the respective schools in the city, otherwise they were mailed in, with a few exceptions where surveys were scanned and emailed. In order to provide a serious incentive for participation, the Department of Mathematics agreed to indeed organize continuing education courses if a need or desire became apparent, and with the topics deemed most needed by the school teachers. No monetary incentives or raffles were provided.

The survey itself had 25 questions on two A4 pages, accompanied by a letter. The 25 questions resulted in 76 individual variables which were entered into and analyzed using SPSS 20 (IBM Corp 2011).

Table 1 summarizes the responses per school type. Austrian higher secondary schools are divided into two main types. There are the common secondary high schools with an education preparing students for possible further studies at universities and applied universities (AHS, Allgemeinbildende Höhere Schule), as well as professionally oriented secondary high schools (BHS, Berufsbildende Höhere Schule) that offer a dual education system combining common topics and apprenticeship in prepration for special professions in technical (HTL) or commercial (HAK) subjects, and also for tourism and home economics (HLW).

Altogether, the response rate across all school types was almost $60 \%$, indicating a strong interest of mathematics teachers in the survey and in the issues surrounding it. However, among the technical secondary schools $H T L$, the response rate was at less than $10 \%$ (only three surveys returned) strikingly low and thus they were removed from some of the further analysis. The technical secondary schools are typically relatively large in size. The authors suspect that the dimensions and buerocracy at these large schools were a prohibitive factor. When reducing the study to the non-technical secondary schools, the response rate was at two thirds $(67.3 \%)$ of the estimated study population. Comparison of the city schools showed a clearly higher response rate among those schools that were visited personally, as compared to those that only received an electronic invitation. It is evident that the time-consuming delivery and pick-up of surveys were important factors in achieving the high response rate.

Table 1: Response numbers and rates per school type. For the school type abbreviations, see Section 2.

$\begin{array}{lrrr}\text { School Type } & \text { Estimated Population Size } & \text { Number of Responses } & \text { Response Rate [\%] } \\ \text { All types } & 247 & 143 & 58 \\ \text { AHS } & 150 & 102 & 68 \\ \text { BHS } & 97 & 41 & 42 \\ \text { HTL } & 39 & 3 & 8 \\ \text { BHS other } & 58 & 38 & 66 \\ \text { All without HTL } & 208 & 140 & 67\end{array}$

\section{Survey results}

Technically, all the mathematics teachers in the state were attempted to be contacted. Thus, the survey may be regarded as a census with nonresponse, rather than a random sample. In 
order to correct for the effects of about one third nonresponse, respondents could be assigned weights according to their school type. A priori, there is no justification to assume that age or gender distributions of mathematics teachers are to resemble those of the general teacher population in the state. Thus, school type is the only stratifying variable for which population totals can be convincingly estimated, as described in the beginning of Section 2 . The response rates of $68 \%$ for $A H S$ teachers, and $66 \%$ for $B H S$ teachers (without technical schools) are almost identical. Consequently, the respective weights would be quasi identical, as well. Therefore, the authors have decided to forego any response weighting for this survey, considering also that the actual response counts are presented and interpreted in a more straightforward manner without weighting.

\subsection{Demographics}

Table 2: Age distribution per school type. For the school type abbreviations, see Section 2. The table shows total counts and column percentages (in parentheses). Some teachers are shared between different schools and the respective proportions are considered at each table entry, resulting in rounding differences for the totals. Three teachers did not provide their age.

\begin{tabular}{lrrrrrr} 
& \multicolumn{3}{c}{ Mathematics Teachers (Sample) } & All Teachers (Statistik Austria 2012b) \\
Age Group [y] & AHS & BHS & All Schools & AHS & BHS & All Schools \\
$<30$ & $19(19 \%)$ & $4(10 \%)$ & $23(17 \%)$ & $125(9 \%)$ & $107(6 \%)$ & $232(7 \%)$ \\
$30-39$ & $17(17 \%)$ & $10(26 \%)$ & $27(19 \%)$ & $302(21 \%)$ & $384(22 \%)$ & $686(21 \%)$ \\
$40-49$ & $25(25 \%)$ & $11(28 \%)$ & $36(26 \%)$ & $394(27 \%)$ & $597(34 \%)$ & $991(31 \%)$ \\
$50-59$ & $34(34 \%)$ & $11(28 \%)$ & $45(32 \%)$ & $535(37 \%)$ & $583(33 \%)$ & $1118(35 \%)$ \\
$60-$ & $6(6 \%)$ & $3(8 \%)$ & $9(6 \%)$ & $84(6 \%)$ & $89(5 \%)$ & $173(5 \%)$ \\
Total & 101 & 39 & 140 & 1440 & 1758 & 3200
\end{tabular}

Table 2 shows the age structure of the sample, compared to that of the total teacher population (not only mathematics teachers) at secondary schools in the State of Salzburg (Statistik Austria $2012 \mathrm{~b}$ ). The only noticeable difference is with regard to the group of under 30 year old teachers, which appear to be overrepresented in the sample. A possible explanation could be the recent lack of mathematics teachers, resulting in recent mathematics graduates being employed at higher proportions than graduates of other subjects. Also, recent graduates from the University of Salzburg may have been more inclined to respond to the survey, as they may still feel a stronger connection to their alma mater. Among all respondents were 57\% women. Among those younger than 40 years of age, even 33 out of $50(66 \%)$ were female.

\subsection{Where did they study - and did it prepare them well for their job?}

Table 3: Number of responding teachers by university where teaching degree was obtained. Four teachers did not provide this information.

$\begin{array}{lrr} & \text { Number } & \text { Percentage } \\ \text { Salzburg } & 114 & 82 \\ \text { Innsbruck } & 2 & 1 \\ \text { Linz } & 6 & 4 \\ \text { Graz } & 5 & 4 \\ \text { Wien (U) } & 6 & 4 \\ \text { Wien (TU) } & 3 & 2 \\ \text { not in Austria } & 3 & 2 \\ \text { Total } & 139 & 100\end{array}$

As Table 3 shows, more than $80 \%$ of the current mathematics teachers responding to the survey have studied at the University of Salzburg. Clearly, this indicates low incoming mo- 
bility of teachers. It would be interesting to compare these numbers to those in other Austria states in order to see whether there is outgoing mobility from Salzburg, or whether generally students strongly tend to become mathematics teachers in the same states where they have studied. Due to the low number of graduates from other institutions in the survey, comparisons of the different universities with regard to their mathematics teacher preparation were not conducted. Also, it did not seem advisable to aggregate graduates from all universities other than Salzburg for comparison purposes.

Table 4 shows to which degree current mathematics teachers considered their university education with regard to statistics and probability meaningful or sufficient.

Table 4: Degree to which respondents found university preparation regarding statistics and probability meaningful or sufficient (counts). Ten teachers did not provide an answer regarding "meaningful", eight did not provide an answer regarding "sufficient". In total, twelve teachers did not provide both answers.

\begin{tabular}{|c|c|c|c|c|c|c|c|}
\hline \multirow[t]{2}{*}{$\begin{array}{l}\text { Number } \\
\text { of teachers }\end{array}$} & & \multicolumn{5}{|c|}{ University preparation sufficient } & Total \\
\hline & yes & 24 & 11 & 0 & 8 & 0 & 43 \\
\hline University & somewhat & 3 & 8 & 6 & 12 & 2 & 31 \\
\hline preparation & don't know & 0 & 3 & 3 & 3 & 3 & 12 \\
\hline meaningful & not so much & 4 & 1 & 3 & 11 & 4 & 23 \\
\hline & no & 1 & 1 & 1 & 2 & 17 & 22 \\
\hline Total & & 32 & 24 & 13 & 36 & 26 & 131 \\
\hline
\end{tabular}

Altogether, the university preparation was considered meaningful or somewhat meaningful by a majority $(56 \%)$ of respondents. However, answers regarding usefulness of the preparation were not at all unequivocal, with $43 \%$ responding positively (yes or somewhat) and $47 \%$ answering negatively (no or not so much). The Spearman rank correlation between both variables $(\hat{\rho}=0.627)$, indicates that generally respondents who considered the university preparation sufficient were also more likely to consider it meaningful.

\subsection{How important are statistics, probability, and computers in today's mathematics teaching?}

More than $70 \%$ of respondents stated that they knew which mathematics standards were required for the 8 th school level. This is important, as mathematics instruction in the following years builds upon these standards. Stratifying by school type differentiated this picture: in the higher vocational schools with business (HLW, Höhere Lehranstalt für Wirtschaftliche Berufe) or tourism focus, only 5 out of 12 responding teachers (42\%) knew the 8th grade standards. In these school types, mathematics was generally not considered as important as in other schools, and it had not been a subject on the school leaving examination. However, this will now change because of the new central school leaving examination (Matura) making mathematics an exam subject for all secondary schools. Altogether, 60\% of respondents said that they new the requirements for the new Matura, and about the same proportion stated that the new Matura would increase the importance of probability and statistics in mathematics instruction.

The new central school leaving examination assumes that pupils will have obtained experience in technology (computer) use before they graduate. Therefore, a closely related question is whether computers are actually used in mathematics instruction. A majority of AHS teachers $(52 \%)$ responded positively (see Table 5). Strikingly low was however the proportion of positive responses among BHS teachers $(22 \%)$. This appears particularly surprising as the BHS is considered more practically oriented and less academic. In this context, more data from the technical schools, which had to be excluded from some of the analyses due to their non-representative low response rates, would be interesting. Based on personal experience, the 
authors conjecture that computer technology is frequently used in mathematics instruction in these schools, and 3 out of the 4 responses from technical schools were affirmative.

Table 5: Use of computer in class instruction (counts). Technical schools excluded (four teachers). Three teachers did not answer the question regarding computer use in the classroom.

$\begin{array}{llrrr}\text { Number } & & \text { School type } & \text { Total } \\ & & \text { AHS } & \text { BHS } & \\ \text { Computer use } & \text { yes } & 53 & 8 & 61 \\ \text { in classroom } & \text { no } & 48 & 27 & 75 \\ \text { Total } & & 101 & 35 & 136\end{array}$

\subsection{What is actually taught in statistics and probability school lessons?}

We asked the mathematics teachers to check on a list of more than 20 topics taken from mathematics curricula which ones are covered in their classes. There was a large spread in responses with some topics only being taught by a few (as few as 4), while others were taught by almost everyone (as many as 128). Also, 27 respondents found that there was not enough time for a comprehensive treatment of probability and statistics in class.

Specifically, about $90 \%$ of respondents said that they covered descriptive statistics, and elementary probability, while combinatorics and conditional probability were each taught by about $70 \%$. Normal and binomial distribution were each introduced by more than $85 \%$, but less than 15\% covered the Poisson distribution. About $40 \%$ taught confidence intervals and $30 \%$ hypotheses tests, but only about $12 \%$ said that they covered $p$-values, and about the same number $(13 \%)$ taught sampling distributions. The normal approximation was introduced by about $60 \%$ of respondents, whereas $20 \%$ mentioned that they specifically covered the central limit theorem. Correlation and linear regression were each covered by about $30 \%$ of respondents (on the survey, these options did not appear directly adjacent). Less than 5\% covered analysis of variance.

\subsection{Continuing education for mathematics teachers}

Perusing continuing education catalogues of the teacher training colleges (Pädagogische Hochschulen) revealed only a small number of events regarding probability and statistics. Thus, it is perhaps not surprising that about two thirds of respondents (see Table 6) expressed a desire to have continuing education events in statistics and probability, that are offered by the Department of Mathematics at the University of Salzburg (which includes the statistics and probability group). Specific topics desired most frequently were those of statistical inference, namely estimation and hypothesis testing.

Table 6: Should the Department of Mathematics at the University of Salzburg offer continuing education for school teachers? One person did not provide an answer.

$\begin{array}{lrr} & \text { Number } & \text { Percentage } \\ \text { yes } & 42 & 30 \\ \text { rather yes } & 54 & 38 \\ \text { don't know } & 23 & 16 \\ \text { rather not } & 12 & 8 \\ \text { no } & 11 & 8 \\ \text { total } & 142 & 100\end{array}$

While there was a general concern about the lack of sufficient continuing education opportunities offered by the teacher training colleges, also two thirds of respondents said that they generally did not take advantage of the teacher training colleges' continuing education offers. Among the teachers at business colleges (Handelsakademie), even as many as $94 \%$ stated that 
they did not use these opportunities, indicating a possible disconnect between desired and offered course topics.

The request for continuing education to be offered by the university department did not differ much between school types and was larger than $60 \%$ for each school type. This was communicated to the Department of Mathematics at the University of Salzburg and has already resulted in the planning of such events. For practical reasons, these should be offered in cooperation with the teacher training colleges. In fact, only $7 \%$ of respondents explicitly stated that they would like for the teacher training colleges not to be involved in such events.

\section{Discussion and outlook}

For a large part, the results summarized above are not surprising. Nevertheless, they provide a glimps at daily work in Salzburg's schools. For example, while just a few years ago, mathematics was a subject taught mostly by men, today almost $60 \%$ of mathematics teachers are female. The age structure of mathematics teachers in Salzburg corresponds closely to that of all teachers in the state. Most of those currently teaching mathematics have obtained their university degree at the University of Salzburg.

Statistics and probability are currently gaining in importance, also reinforced by the requirements of the new central Austrian school leaving examination. Mathematics teachers would like to see continuing education opportunities in statistics and probability, and these are not yet sufficiently provided by the teacher training colleges. Here, the university departments of mathematical sciences, not only in Salzburg, can position themselves as competent partners in providing comprehensive and competent continuing education opportunities for secondary school teachers, ideally in cooperation with nearby teacher training colleges.

Most teachers responding to the survey discussed basic aspects of statistics and probability in their mathematics school lessons, while advanced material such as the sampling distributions, $p$-values, and the central limit theorem was taught by less than a quarter, and special topics such as analysis of variance only by very few. Several teachers mentioned lacking sufficient time for an adequate coverage of statistics and probability in class.

It would be interesting to conduct a similar study in other Austrian states or even beyond the Austrian borders, and compare the results, also with regard to the universities preparing students to become mathematics teachers. However, in light of the current structural reforms affecting secondary education in Austria, the results of such studies would certainly depend on the degree with which changes have been implemented and thus they are expected to change over the coming years.

\section{Acknowledgement}

The study was supported by a large majority of mathematics teachers at the secondary schools in the Austrian Federal State of Salzburg. These mathematics teachers have contributed greatly to its success, and the authors would like to express their sincere gratitude to all participants, as well as to the administrators who have provided support at different stages of the study. Furthermore, several helpful and constructive suggestions by Prof. Andreas Quatember (JKU Linz, Department of Applied Statistics) and by the AJS review team have resulted in a much improved manuscript.

\section{References}

Blömeke S, Kaiser G, Lehmann R (eds.) (2008). Professionelle Kompetenz angehender Lehrerinnen und Lehrer. Waxmann, Münster, Germany. 
bmukk (2003). Verordnung der Bundesministerin fÃijr Bildung, Wissenschaft und Kultur, mit der Lehrpläne im schulischen Bildungsbereich geändert werden; (Wochenstundenentlastungs- und Rechtsbereinigungsverordnung 2003), Stand 23.2.200\%. BMUKK, Wien, Austria.

IBM Corp (2011). IBM SPSS Statistics for Windows, Version 20.0. IBM Corp, Armonk, NY, USA.

Krauss S, Brunner M, Kunter M, Baumert J, Blum W, Neubrand M, Jordan A (2008). "Pedagogical Content Knowledge and Content Knowledge of Secondary Mathematics Teachers." Journal of Educational Psychology, 100(3), 716.

Statistik Austria (2012a). Lehrerinnen und Lehrer im Schuljahr 2011/12 (insgesamt). Statistik Austria, Wien, Austria.

Statistik Austria (2012b). Lehrerinnen und Lehrer im Schuljahr 2011/12 nach dem Alter. Statistik Austria, Wien, Austria.

Voit W (2013). Stochastik im Mathematikunterricht. Theoretische Überlegungen und empirische Untersuchungen über den Status der Statistik und Wahrscheinlichkeitslehre im Mathematikunterricht an Salzburgs höheren Schulen. Universität Salzburg: Diplomarbeit., Salzburg, Austria.

\section{Affiliation:}

Wolfgang Voit

Fachbereich Mathematik

University of Salzburg

A-5020 Salzburg, Austria

E-mail: wolfgang.voit@gmx.at

\section{Austrian Journal of Statistics}

published by the Austrian Society of Statistics

Volume 44

January 2015 http://www.ajs.or.at/

http://www.osg.or.at/

Submitted: 2014-02-10

Accepted: 2014-07-17 